\title{
Team Members and Patients' Views on Cost-effectiveness of (Integrated) Clinical Pathway
}

\author{
Karmen Erjavec* ${ }^{*}$ \\ Faculty of Health Sciences, University of Novo Mesto, Novo Mesto, Slovenia
}

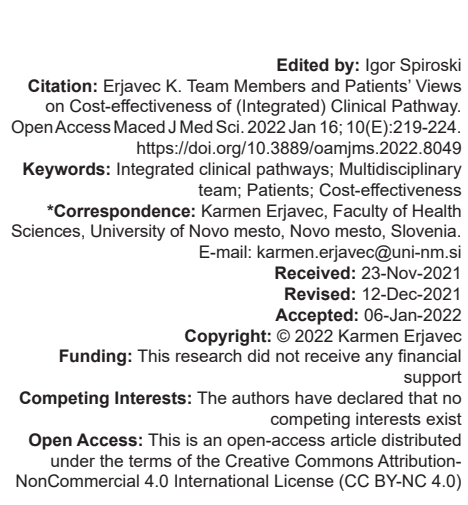

Introduction

Today, health-care providers seeking to meet the needs of a growing number of patients must keep pace with rapidly evolving treatment modalities to achieve positive patient outcomes while meeting the increasing demands of government and private payers. To do so, clinical pathways (CPs) have become an important tool to enable informed decision-making and provide more efficient, cost-effective, and value-based care [1]. CP makes the cost of care more predictable for different types of patients and is an excellent tool to help health care providers and payers estimate costs and negotiate appropriate bundled payments [2]. Over the past decade, the concept of the "integrated" CP (ICP) has been used to emphasize the work of multidisciplinary teams that reach beyond the boundaries of individual health facilities to include all key health-care professionals and other care providers [3], [4], [5], [6], [7]. However, other authors emphasize that the term "ICP" is no longer necessary as care pathways are integrated by definition, as fragmented care pathways cannot exist [8]. The term "clinical" care pathway is reserved for the care pathway within a clinic or a 24-h department of a hospital [8]. Although there is no single definition of ICPs, they can be described as a complex intervention for shared decision-making and organization of healthcare processes for a well-defined group of patients during a well-defined period of time, including an explicit statement of the goals and key elements of care based on evidence, best practice, and patients' expectations and characteristics [4].

Several systematic reviews have found positive effects for CPs [9], [10], [11], but little is yet known about the economic impact [1], [12]. In recent years, few studies have investigated the cost-effectiveness of ICPs, and in these studies, the patient groups and settings in which ICPs were used vary widely [13], [14], [15], [16], [17]. Recently, Everink et al. [2] conducted a cohort study over a 9-month period examining intervention costs, health-care costs, and costs to patients and their families. Outcomes were measured by dependency in activities of daily living and quality-adjusted life years. They found that the cost-effectiveness of an ICP was good for patients with complex health problems who were transferred from a hospital, geriatric rehabilitation facility, and primary care.

In the countries of the Central and South-east Europe, clinics are trying to introduce ICPs. In Slovenia, 
CPs have already been generally introduced, but there is a lack of ICPs that involve all the key actors (health professionals and other professions) needed to provide comprehensive care to the patient. Since attitudes lead to behavioral intentions, which in turn lead to actual behavior [18], it is important to understand the attitudes of all involved in health care toward cost-effectiveness to identify opportunities for the introduction of ICPs in the future. Due to the ageing of the population and the associated increased incidence, one of the frequently treated diseases in older patients is total hip arthrosis [19]. In the absence of studies on the cost-effectiveness of ICPs, the aim of this study was to determine the opinion of team members treating patients with total hip arthroplasty and their patients about the practice of costeffectiveness of existing CP and the cost-effectiveness of ICP that might be introduced in the future.

\section{Methods}

A mixed descriptive quantitative and qualitative approach was used. Data collection was part of the project "Impact of ICPs on patient outcomes, communication and cost effectiveness" funded by the Slovenian Research Agency (No. L7-2631-3824-2020). The research was approved by the Commission for Medical Ethics of the RS (No. 0120-189/2021/3).

\section{Quantitative approach}

At the request of the participants, the questionnaire was distributed in printed and online form. The questionnaires were collected from June 7 to July 15,2021 in the multidisciplinary team for total hip arthroplasty at the General Hospital of Novo mesto (SBNM), which includes all members involved in the treatment of total hip arthroplasty patients. This hospital was selected because it represents a typical general hospital in Slovenia, one of ten.

A survey was conducted among 61 team members. The sample was dominated by women $(82.1 \%)$. Most participants were in the age group of $31-50$ years $(60.6 \%)$ and $31-40$ years $(39.4 \%)$. The majority of participants had higher vocational education $(43.9 \%), 31.8 \%$ had a secondary education and $24.2 \%$ had a university or postgraduate degree. The questionnaire was completed by nursing assistants who had completed secondary school $(31.8 \%)$, registered nurses or graduated nurses $(39.4 \%)$, physicians $(9.1 \%)$, and other professionals (19.7\%) such as physiotherapists $(4.8 \%)$ and clinical pharmacists, psychologist, social worker, clinical dietician, and health administrators.

For data collection, a structured questionnaire based on similar questionnaires was used [13], [18], [19], adapted, and supplemented for the needs of the study. The first question measured agreement with the statement about the impact of ICP on the cost-effectiveness of the treatment (Table 1) on a 5-point scale from 1 - "I don't agree at all" to 5 - "I totally agree." To identify the practice of cost-effectiveness of the existing $\mathrm{CP}$, the next question related to the frequency of prioritizing cost-effectiveness over quality of treatment within the existing $\mathrm{CP}$ and the impact of $\mathrm{CP}$ on cost-effectiveness and time (Table 1) on a 5-point scale from 1 - "Never" to 5 - "Very often." The last set of questions, which included sociodemographic variables, contained five questions on gender, age, education level, years of employment, and professional group. The reliability of the instrument was acceptable $(\alpha=0.819)$.

Descriptive analysis and analysis of variance were calculated. Data were coded and analyzed using SPSS 24.0 .

\section{Qualitative study}

All members of the health-care team treating patients with total hip arthroplasty at SBNM were invited to participate in the focus groups and 11 nurses with completed secondary education participated. The purpose of using the focus group was to verify the data obtained from a quantitative survey and to identify an in-depth view of team members' perceptions of costeffectiveness. As many individual professionals were unable to participate in the focus groups due to different time commitments and the workload of the COVID-19 epidemic, we also conducted 12 in-depth interviews with physicians (four), head nurses (one), physiotherapists (one), psychologists (one), social workers (one), pharmacists (one), clinical dietitians (one), clinical pharmacists (one), and health administrators (one). Focus groups and in-depth interviews were conducted in September-October 2021 at SBNM. Two main themes were addressed: (1) The assessment of the importance of cost-effectiveness of the ICP and (2) the experience of cost-effectiveness in everyday work, especially within current CP for total hip arthroplasty. The focus group and in-depth interviews discussions were recorded with prior consent of the participants and the (anonymized) statements of the participants were transcribed.

In October 2021, we conducted in-depth interviews with 20 patients with total hip arthroplasty who had undergone surgery in the SBNM Orthopaedic Department. All patients who underwent surgery for total hip arthroplasty between October 11, 2021 and October 29, 2021 were invited for in-depth interviews and all responded. The interviews were conducted by discharge patients from hospital. Participants were aged between 51 and 91 years $(M=67), 14$ men and 6 women. The main topic was the experience of costeffectiveness within their health treatment. The in-depth interview, which lasted on average about $60 \mathrm{~min}$, was recorded with prior consent of the participants and 
Table 1: Frequency of use of cost-effectiveness and importance of cost-effectiveness of (I) CP

\begin{tabular}{|c|c|c|c|c|c|c|c|}
\hline \multirow[t]{2}{*}{ Statements } & \multicolumn{5}{|l|}{ Answers (\%) } & \multirow[t]{2}{*}{ M } & \multirow[t]{2}{*}{ SD } \\
\hline & Never & Rarely & Uncommon & Often & Very often & & \\
\hline We put the cost-effectiveness of treatment above the quality of treatment & $18(29.0)$ & $7(11.5)$ & $12(19.7)$ & $6(9.8)$ & $18(29.6)$ & 2.75 & 2.95 \\
\hline We use of CP to reduces the cost of treating patients & $7(11.5)$ & $3(4.9)$ & $14(23.0)$ & $12(19.7)$ & $25(41.0)$ & 4.15 & 2.97 \\
\hline \multirow[t]{2}{*}{ We use of $\mathrm{CP}$ to reduces the time needed to treat patients } & $5(8.2)$ & $3(4.9)$ & $14(23.0)$ & $10(16.4)$ & $28(47.5)$ & 3.79 & 2.88 \\
\hline & I do not agree at all & I do not agree & I cannot Decide & I agree & I completely agree & & \\
\hline The use of ICP has a positive impact on the cost-effectiveness of patient & $7(10.4)$ & $2(3.0)$ & $12(17.9)$ & $35(52.2)$ & $11(16.4)$ & 3.81 & 2.51 \\
\hline
\end{tabular}

care

the (anonymized) statements of the participants were transcribed.

The data were analyzed using thematic analysis. Due to the limited textual possibilities to present qualitative results, we only present those findings of the qualitative analysis that explain or further illuminate the results of the quantitative analysis.

\section{Results}

Table 1 shows that participants occasionally prioritize cost-effectiveness over quality of health care $(\mathrm{M}=2.75)$, but one-third also reported that they never do so and one-third very often. They frequently use CP to reduce costs $(M=4.15)$ and time spent treating patients $(M=3.79)$. They also believe that using ICP has a positive impact on the cost-effectiveness of patient care $(M=3.81)$.

Table 2 shows that there were no significant differences in the frequency of use of cost-effectiveness and importance of cost-effectiveness of (I) CP among the different groups in terms of length of employment and education. There is significant difference in the prioritization of cost-effectiveness over quality of health care in relation to occupational groups. Nurses with completed secondary school were significantly more likely to report prioritizing cost-effectiveness of care over quality of care than nurses with completed higher school education, physicians, and others.

\section{Qualitative approach}

\section{Health-care team members}

The potentially positive impact of ICPS on costeffectiveness was also confirmed by the statements of the team members in the focus groups and the in-depth

Table 2: Results of ANOVA

\begin{tabular}{llll}
\hline Statements & $\begin{array}{l}\text { Professional } \\
\text { group }\end{array}$ & $\begin{array}{l}\text { Years of } \\
\text { employment }\end{array}$ & Education \\
$\begin{array}{l}\text { We put the cost-effectiveness of } \\
\text { treatment above the quality of } \\
\text { treatment }\end{array}$ & $2.75^{\star}$ & 1.190 & 1.191 \\
$\begin{array}{l}\text { We use of ICP reduces the cost of } \\
\text { treating patients }\end{array}$ & 1.003 & 1.147 & $1-166$ \\
$\begin{array}{l}\text { We use of CP reduces the time } \\
\text { needed to treat patients }\end{array}$ & 1.130 & 1.430 & 1.24 \\
$\begin{array}{l}\text { The use of CP has a positive } \\
\text { impact on the cost-effectiveness } \\
\text { of patient care }\end{array}$ & 0.620 & 1.611 & 1.671 \\
$\begin{array}{l}\text { (F)-value: }{ }^{* \star} \mathrm{p}<0.001,{ }^{* *} p<0.01,{ }^{*} \mathrm{p}<0.05, \text { ICP: Integrated clinical pathways, CP: Clinical pathway, } \\
\text { ANOVA: Analysis of variance. }\end{array}$ & &
\end{tabular}

interviews. However, they unanimously emphasized that due to the general lack of staff, the introduction of ICPs is only possible with the recruitment of a person to coordinate, monitor, and evaluate the ICP process. A typical statement comes from a physician:

The biggest problem is that there is lack of staff. There is too much work and that is why we are burn out. In this situation, there is no chance to introduce ICP. We need more people in all areas of work, especially more nurses. To introduce an ICP, we need at least one coordinator whom everyone respects and obeys. Moreover, this coordinator should also review and correct the pathway regularly. There is no other way.

Participants pointed out that 5 years ago (2016), when the hospital was going through a financial restructuring, they were put under enormous pressure by the hospital management to reduce labor and material costs. Over time, they have internalized and normalized the pressure by monitoring costs regularly. They pointed out that they choose cheaper materials, but not at the expense of patient care. The typical statement comes from a nurse who has completed secondary school:

I feel a pressure for cost-effectiveness. Five years ago, when the restructuring started, it was really hard and I felt a lot of stress. We were not used to it; we did not even learn about it during our studies. Now it is better, I got used to it. We all got used to it. Now I look at every procedure, but it could be cheaper, what could be saved? For example, we have gloves of inferior quality. However, I must stress that this is never, really never at the expense of the patients.

All participants also pointed out that the introduction of a CP for total hip arthroplasty 5 years ago has had a significant impact on the treatment costs. Above all, the improved coordination of the health-care team's work and the introduction of the pre-operative school, in which patients are given all the important information about the procedure, have significantly shortened the length of hospital stay in the hospital. "It can be seen that the length of stay is reduced from 2 to 3 days to 1 day. Moreover, we have achieved this through better coordination and the pre-operative school where we teach them everything: What examinations they need to bring, they know the whole procedure, the exercises, the conditions for discharge, etc.," said the head nurse.

All participants repeatedly stressed that management saves too much at the expense of staff because there is a shortage of staff, especially nurses. 
"We are not enough for such hard work. We work like crazy, all day, and we are burnt out. However, here, we really do not have enough support from the management who are saving on us! We need to hire more nurses," said the head nurse.

\section{Patients}

The patients who had a total hip arthroplasty in the hospital years ago compared a new experience with the previous one and evaluated the cost-effectiveness positively. They referred to the pre-operative school that reduced their length of stay in hospital and prepared them for surgery and discharge. A typical statement was: "I see a better cost-effectiveness because I had a similar operation on my left leg 3 years ago. I had a preoperative school now where everything was explained to us, from surgery to rehabilitation, and what we should eat. And I stay in hospital for less time now. I welcome that!"

Most patients also pointed out the negative aspect of cost-effectiveness that staff has too little contact with patients: "The nurses are just going back and forth quickly, no one really cares!" Two patients said that the savings were in nutrition, as they were told at school before surgery to eat enough protein, but they were given mainly carbohydrates: "Yes, they save on us. You can see that quite clearly in the food. At school, we were told to eat protein for breakfast, for example, cheese and we were given bread with jam. How is that now?"

\section{Discussion}

As there is a research gap regarding the attitudes of members of the multidisciplinary team and their patients toward the cost-effectiveness of (I) CP, the first study was conducted using a mixed methods approach combining a quantitative staff survey with qualitative in-depth interviews and focus groups alongside in-depth interviews with patients with total hip arthroplasty. The combination of approaches was useful as it provided a broader and deeper insight into the use of (I) CP for the cost-effective treatment of patients.

What did the results show about the use of the existing $\mathrm{CP}$ for total hip arthroplasty? It showed that team members occasionally prioritize costeffectiveness over quality of health care; however, onethird of them reported that they never do and one-third that they very often do. The results also showed that they frequently use CP to reduce the cost and the time spent treating patients. Nurses who have completed secondary education are significantly more likely to prioritise the cost-effectiveness of health care over the quality of health care in their daily work than nurses with higher education, physicians, and others. The fact that nurses with secondary education are more likely to prioritize cost-effectiveness over quality than other professional groups can be explained by the results of the focus group, which showed that these nurses feel the shortage of staff the most. In fact, nurses and patients pointed out that due to staff cuts, nurses had too little contact with patients.

The results also showed that all participants felt a lot of pressure from hospital management to reduce costs during the financial restructuring. However, they eventually internalized the pressure and monitor costs regularly. For them, some of the cost reductions, such as using cheaper materials, were really necessary, but others, such as cutting staff, were too radical.

The results also revealed that participants believe that the use of ICP has a positive impact on the cost-effectiveness of patient care. However, participants reported that due to lack of staff, they do not see a way to implement ICP in all its complexity without hiring an additional person to coordinate, monitor, and evaluate the ICP process.

The patients evaluated the cost-effectiveness positively, as the pre-operative school shortened their time in hospital and prepared them for complete treatment process. However, most patients also pointed out the negative aspect of cost-effectiveness, namely, that staff, especially nurses had too little contact with patients. This is in line with the previous studies which have shown that a shortened hospital stay was positively received by patients, in contrast to other shortenings which were less positively received [19], [20].

The shortage of physicians and nurses is a major health system challenge in Slovenia as stated in State of Health in the EU: Slovenia [21] as the number of doctors in Slovenia (3.1/1000 population) is well below the EU average and the number of nurses includes nursing staff who have completed only vocational training and are not compliant with the directive on regulated health professions [22]. The understaffing leads to increased overwork and burnout. Such conditions lead to de-personalization and lack of compassion as the main component of the burnout which is increasingly recognized and increasingly common not only in Slovenia but worldwide [22], [23], [24]. Hospital-based health-care workers have experienced substantially increased burnout during the COVID-19 pandemic. For example, before the COVID-19 pandemic, severe burnout was typically found in Canadian in 20-40\% of health-care workers; however, by spring 2021 , rates $>60 \%$ were found in physicians, nurses, and other health-care professionals [24]. Therefore, the maintenance of the health professions will benefit from the additional employment of health-care professionals and by retaining current staff through financial compensation and fostering supportive workplace characteristics including good communication and supportive leadership, continued professional 
development, appropriate autonomy, and collegial relationships among team members.

The main limitation is that only one Slovenian hospital participated in the study. The results can only give us an insight into the challenges of implementing ICP and the role of cost-effectiveness in Slovenia and in comparable Eastern European countries. Another important limitation concerns the crisis situation related to the COVID-19 epidemic, where the work, communication, and collaboration were different than before the epidemic.

\section{Conclusion}

As there is a research gap regarding the attitudes of team members and their patients toward the cost-effectiveness of ICP, the first study showed that team members treating patients with total hip arthroplasty in a typical Slovenian hospital have a positive attitude toward the cost-effectiveness of ICP. Occasionally, they prioritize cost-effectiveness over quality of health care, especially nurses who have completed secondary school. Both team members and patients emphasized that team members, especially nurses, have too little contact with patients due to staff shortages. Therefore, additional recruitment of health workers is urgently needed.

\section{References}

1. Broughton El. The "how" and "why" of cost-effectiveness analysis for care pathways. Int J Care Pathways. 2011;15(3):7681. https://doi.org/10.1258/jicp.2011.011004

2. Everink IH, van Haastregt JC, Evers SM, Kempen GI, Schols JM. An economic evaluation of an integrated care pathway in geriatric rehabilitation for older patients with complex health problems. PLoS One. 2018;13(2):e0191851. https://doi. org/10.1371/journal.pone.0191851 PMid:29489820

3. Cook S, Scott M. Framework for the implementation of integrated care pathways: Part 2. J Integ Care Pathways. 2005;9(1):39-45.

4. Hogan C, Barry M, Burke M, Joyce P. Healthcare professionals experiences of the implementation of integrated care pathways. Int J Health Care Qual Assur. 2011;24(5):334-47. https://doi. org/10.1108/09526861111139179 PMid:21916088

5. Busetto L, Luijkx K, Calciolari S, Ortiz LG, Vrijhoef HJ. Barriers and facilitators to workforce changes in integrated care. Int $J$ Integ Care. 2018;18(2):17. https://doi.org/10.5334/ijic.3587 PMid:30127701

6. Sleeman KE, Koffman J, Bristowe K, Rumble C, Burman R, Leonard S, et al. It doesn't do the care for you: A qualitative study of health care professionals' perceptions of the benefits and harms of integrated care pathways for end of life care.
BMJ Open. 2015;5(9):e008242. https://doi.org/10.1136/ bmjopen-2015-008242

PMid:26369795

7. Seys D, Panella M, Van Zelm R. Care pathways are complex interventions in complex systems: New European pathway association framework. Int J Care Coordinat. 2019;22(1):5-9.

8. Schrijvers G, van Hoorn A, Huiskes N. The care pathway: Concepts and theories: An introduction. Int $\mathrm{J}$ Integ Care. 2012;12(1):e192. https://doi.org/10.5334/ijic.812 PMid:23593066

9. Allen D, Gillen E, Rixson L. Systematic review of the effectiveness of integrated care pathways: What works, for whom, in which circumstances? Int J Evid Based Healthc. 2009;7(2):61-74. https://doi.org/10.1111/j.1744-1609.2009.00127.x PMid:21631848

10. Van Herck P, Vanhaecht K, Sermeus W. Effects of clinical pathways: Do they work? Int J Care Coordinat. 2004;8(3):95-105.

11. Deneckere S, Euwema M, Van Herck P, Lodewijckx C, Panella M Sermeus W. Care pathways lead to better teamwork: Results of a systematic review. Soc Sci Med 1982. 2012;75(2):264-8. https://doi.org/10.1016/j.socscimed.2012.02.060 PMid:22560883

12. Nolte E, Pitchforth E. What is the Evidence on the Economic Impacts of Integrated Care? Copenhagen: World Health Organization; 2014.

13. Dautremont JF, Rudmik LR, Yeung J, Asante T, Nakoneshny SC Hoy M. Cost-effectiveness analysis of a postoperative clinical care pathway in head and neck surgery with microvascular reconstruction. J Otolaryngol Head Neck Surg. 2013;42:59.

14. Holtzer-Goor KM, Gaultney JG, van Houten P, Wagg AS Huygens SA, Nielen MM, et al. Cost-effectiveness of including a nurse specialist in the treatment of urinary incontinence in primary care in the Netherlands. PLoS One. 2015;10(10):e0138225. https://doi.org/10.1371/journal.pone.0138225 PMid:26426124

15. Krummenauer F, Guenther KP, Kirschner S. Cost-effectiveness of total knee arthroplasty from a health care providers' perspective before and after introduction of an interdisciplinary clinical pathway-is investment always improvement? BMC Health Serv Res. 2011;11:338. https://doi.org/10.1186/1472-6963-11-338

16. Lin YK, Chen CP, Tsai WC, Chiao YC, Lin BY. Cost-effectiveness of clinical pathway in coronary artery bypass surgery. J Med Syst. 2011;35(2):203-13. https://doi.org/10.1007/s10916-009-9357-7 PMid:20703569

17. Bechler CJ, Tormala ZL, Rucker DD. The attitude-behavior relationship revisited. Psychol Sci. 2021;32(8):1285-97. https:// doi.org/10.1177/0956797621995206 PMid:34309418

18. Lankhorst NE, Damen J, Oei EH. Incidence, prevalence, natural course and prognosis of patellofemoral osteoarthritis: The cohort hip and cohort knee study. Osteoarthritis Cartilage. 2017;25(5):647-53. https://doi.org/10.1016/j.joca.2016.12.006 PMid:27940216

19. Wrenn SM, Cepeda-Benito A, Ramos-Valadez DI, Cataldo PA Patient perceptions and quality of life after colon and rectal surgery: What do patients really want? Diseases Colon Rectum. 2018;61(8):971-8. https://doi.org/10.1097/ DCR.0000000000001078 PMid:29944576

20. Fatima I, Humayun A, Anwar MI, Iftikhar A, Aslam M, Shafiq M How do patients perceive and expect quality of surgery, diagnostics, and emergency services in tertiary care hospitals? An evidence of gap analysis from Pakistan. Oman Med J. 2017;32(4):297-305. https://doi.org/10.5001/omj.2017.58 PMid:28804582 
21. State of Health in the EU: Slovenia. European Commission; 2020 Available from: https://www.efaidnbmnnnibpcajpcglclefindmkaj/ viewer.html?pdfurl=https $\% 3 \mathrm{~A} \% 2 \mathrm{~F} \% 2 \mathrm{Fec}$.europa.eu $\% 2$ Fhealth $\% 2$ Fsites $\% 2$ Fdefault $\% 2$ Ffiles $\% 2$ Fstate $\% 2 F$ docs $\% 2 F 2019$ chp_sl_english.pdf\&clen $=2886654$ \& chunk=true [Last accessed on 2021 Oct 31].

22. De Hert S. Burnout in healthcare workers: Prevalence, impact and preventative strategies. Local Reg Anesth. 2020;13:171-83. https://doi.org/10.2147/LRA.S240564

PMid:33149664
23. Leskovic L, Erjavec K, Leskovar R, Vukovič G. Burnout and job satisfaction of healthcare workers in Slovenian nursing homes in rural areas during the COVID-19 pandemic. Ann Agric Environ Med. 2020;27(4):664-71. https://doi.org/10.26444/ aaem/128236

PMid:33356076

24. Maunder RG, Heeney ND, Strudwick G. Burnout in hospitalbased healthcare workers during COVID-19. Sci Br Ontario COVID-19 Sci Adv Table. 2021;2:46. 